
$\angle$ Research Square
Preprints are preliminary reports that have not undergone peer review.
They should not be considered conclusive, used to inform clinical practice,
or referenced by the media as validated information. \title{
Study

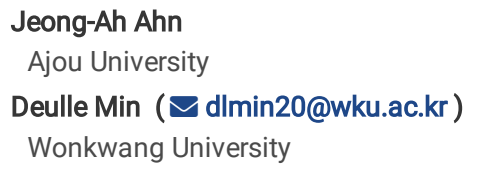

The Benefits of Physical Activity on Indicators of Cardiovascular Risk in Community-Dwelling Older Adults with Hypertension in Korea: A Longitudinal

\section{Research Article}

Keywords: Aged, Physical Activity, Older Adults, Hypertension, Cardiovascular Diseases

Posted Date: January 25th, 2021

DOI: https://doi.org/10.21203/rs.3.rs-149823/v1

License: () (1) This work is licensed under a Creative Commons Attribution 4.0 International License. Read Full License 


\section{Abstract}

Purpose: The study aimed to explore the effects of physical activity on indicators for cardiovascular risk in a sample of community-dwelling older adults with hypertension.

Methods: This longitudinal study used data collected from the Elderly Cohort Database of the National Health Insurance Service in South Korea between 2002 and 2013. Participants included 10,588 older adults ( $\geq 60$ years) with hypertension. Data assessing self-reported physical activity, blood pressure, fasting blood glucose, body mass index, and total cholesterol levels throughout the 12-year study were extracted from the original database and analyzed. Participants were categorized into 4 groups based on the reported changes in physical activity over time; Group I (totally inactive), II (inactive to active), III (active to inactive), and IV (totally active). Cox proportional hazard model was used to confirm the risk of cardiovascular indicators over time in each group.

Results: Participants' mean age was 64.2 years in the initial year of 2002. The number of participants in Groups I, II, III, and IV was 4032, 2697, 1919, and 1940, respectively. Group IV showed a significant decline in risk for uncontrolled hypertension compared to Group I (HR = 0.87, 95\% Cl [0.800-0.948]). Group II showed a significant decrease in risk for uncontrolled diabetes compared to Group I ( $\mathrm{HR}=0.94,95 \% \mathrm{Cl}[0.888-0.999])$.

Conclusions: Physical activity is an essential non-pharmacological and self-management intervention that can be easily implemented among older adults with hypertension. Healthcare providers should be aware of the importance of older adults' physical activity and encourage them to perform and maintain it steadily for better long-term cardio-metabolic outcomes.

\section{Introduction}

The population of older adults is expected to grow from 900 million, representing approximately $12 \%$ of the world's population, in 2015 to 2 billion, approximately $22 \%$ of the world's population, in 2050 worldwide [1]. South Korea is one of the rapidly becoming aging societies. In 1980 , the number of older adults accounted for only $3.8 \%$ of South Korea's population, but in 2019 , it reached $15.7 \%$, with the percentage expected to rise to $33.9 \%$ in 2040 and $46.5 \%$ in 2067 [2]. Consistent with the increase in the older population, the prevalence of chronic diseases has risen. A 2008 survey of older adults reported that the average number of chronic diseases in this population was 2.1 [3], which increased to 2.7 in 2017 [4]. In particular, the prevalence of hypertension in older adults had increased to $59 \%$ in 2017 , indicating that over half of older adults in Korea have high blood pressure (BP) [4].

Hypertension is the most common chronic disease among adults and older people, with 1.13 billion worldwide, and is considered the most common and powerful risk factor for developing cardiovascular disease (CVD) [5, 6]. CVD is the leading cause of death globally, accounting for $31 \%$ of deaths worldwide in 2016 [7]. The risk factors for CVD include increased age, smoking, alcohol consumption, obesity, hypertension, diabetes, dyslipidemia, and sedentary lifestyle $[8,9]$.

Physical activity is considered as an essential recommendation for BP control in patients with hypertension in many studies, and its importance was supported in a meta-analysis of 27 interventions with patients diagnosed with hypertension [10, 11]. For example, one intervention reported that physical activity (i.e., aerobic training) in 52 postmenopausal women with hypertension (mean age of 64 years) significantly decreased systolic BP over 12 weeks [12]. Another study compared the cardiovascular risks of men with hypertension who played 1 hour of soccer twice a week and men who did not, showing that systolic and diastolic BPs in soccer group decreased by $12 \mathrm{mmHg}$ and $8 \mathrm{mmHg}$, respectively, over 6 months [13].

However, few studies have reported the longitudinal effects of physical activity in older people with hypertension on their overall CVD risk factors, such as diabetes, dyslipidemia, and obesity. For physically independent older adults in the community, measuring daily physical activity rather than the amount of short-term exercise during their participation in an intervention program is important [14]. Furthermore, most studies of community-based physical activity intervention have yet to explore long-term effects that extend beyond a year [11]. Therefore, this study's objective was to explore the long-term effects of physical activity on CVD indicators in community-dwelling hypertensive older adults.

\section{Materials And Methods Study design and participants}

A secondary data analysis of a prospective longitudinal study was conducted using the Elderly Cohort Data of the National Health Insurance Service in South Korea between 2002 and 2013. This representative survey in Korea was originally designed to analyze the risk factors and prognosis of senile diseases and included socioeconomic information, hospital-use history, and diverse health examination results.

The participants in this study were 10,588 older adults (over 60 years of age) with hypertension. This Elderly Cohort Data surveyed the number of days of physical activity per week in 2002-2008, and the number of days participants engaged in intense, moderate, and walking activity per week in $2009-2015$. Therefore, we identified physical activity as "yes" or "no", regardless of its time and intensity. Participants were categorized into 4 groups by their changes in physical activity presence or not over time. Group I included the people who reported that they did not engage in physical activity in their daily life throughout the assessment period of 2002-2013 (the totally inactive group). Group II included those who did not engage in physical activity in 2002 but began to participate in physical activity by 2013 (the inactive to active group). Group III included those who reported that they were physically active in 2002 but did not sustain their participation in physical activity when assessed in 2013 (the active to inactive group). Finally, Group IV included those who reported remaining physically active throughout 2002-2013 (the totally active group).

\section{Variables}




\section{Blood pressure}

BP was measured as systolic/diastolic pressure $(\mathrm{mmHg})$ on the participants. According to the European Society of Hypertension, BP over $160 / 100 \mathrm{mmHg}$ is considered Stage 2 (more severe) hypertension [15]; therefore, BP measurements that were 160/100mmHg or higher were used as the criteria of uncontrolled BP in this study.

\section{Blood glucose}

In the cohort survey, pre-meal plasma glucose was checked in 2002-2010, and fasting plasma glucose was measured in 2011-2013. Blood glucose was considered to be controlled if it was less than $100 \mathrm{mg} / \mathrm{dL}$ [16], so blood glucose greater than $100 \mathrm{mg} / \mathrm{dL}$ was categorized as uncontrolled glucose in this study.

\section{Body mass index}

Height $(\mathrm{cm})$ and weigh $(\mathrm{kg})$ were measured on the participants. BMI was calculated from the data and was categorized as being normal or obese using the cut-off value of $25 \mathrm{~kg} / \mathrm{m}^{2}$ [17].

\section{Total cholesterol}

Total cholesterol level was measured for the participants. Participants were categorized as normal or having hypercholesterolemia using the cut-off value of $200 \mathrm{mg} / \mathrm{dL}[9]$.

\section{Covariates}

Age, gender, and economic status were identified as demographic characteristics. Economic status was divided into 4 groups: Low, Lower-Middle, UpperMiddle, and High. Smoking and alcohol consumption were included as characteristics of participants' health behaviors. The number of comorbidities and family history of related diseases (i.e., hypertension, diabetes, heart disease, and cerebral disease) were included as disease-related characteristics.

\section{Data analyses}

Data cleaning and analysis was performed using SPSS version 23.0 (IBM SPSS Statistics, Armonk, NY). Demographic characteristics, health behaviors, and disease-related characteristics in 2002 were reported using descriptive statistics, such as frequency (percentage) and mean (standard deviation). Chi-square tests and one-way ANOVA were used to analyze differences among the physical activity groups. In addition, the Kaplan-Meier method was used to analyze the time to change from controlled to uncontrolled for BP and glucose level and from normal to high for BMI and total cholesterol level. The significance of the analyzed curves was tested using the log-rank test. A Cox proportional hazard model was also used to confirm the risk of cardiovascular indicators over time in each group.

\section{Ethical considerations}

This study was approved by the institutional review board of XX University (IRB No. AJIRB-SBR-EXP-19-127). After receiving approval, a request was made to access the Elderly Cohort Data to the National Health Insurance Data Sharing Services. All data were de-identified before conducting the analysis, so personal identification was protected.

\section{Results}

\section{General characteristics among physical activity groups at baseline}

At baseline in 2002, the mean ages of Group I (the totally inactive group), II (the inactive to active group), III (the active to inactive group), and IV (the totally active group) were $64.58,64.05,64.13$, and 63.67 years, respectively. Group IV was significantly younger than the other three groups $(F=24.43, p<.001)$. Women in Groups I, II, III, and IV represented $58.9 \%, 54.8 \%, 39.4 \%$, and $35.5 \%$ of the sample, respectively $\left(\chi^{2}=401.00, p<.001\right)$. Regarding economic status, people with high economic status in Groups I, II, III, and IV accounted for $23.9 \%, 25.6 \%, 31.9 \%$, and 35.1\%, respectively $\left(\chi^{2}=116.66, p<.001\right)$. In addition, there showed differences in smoking $\left(\chi^{2}=57.32, p<.001\right)$ and alcohol consumption $\left(\chi^{2}=199.16, p<.001\right)$ among the physical activity groups.

The mean number of comorbidities ranged from 0.20 to 0.24 across the 4 groups, and individuals in Group III and IV had significantly more diseases ( $F=3.99$, $p=.008)$. Further, the prevalence of family history of hypertension $\left(X^{2}=42.87, p<.001\right)$, diabetes $\left(X^{2}=32.37, p<.001\right)$, heart disease $\left(X^{2}=19.65, p<.001\right)$, and cerebral disease $\left(\chi^{2}=43.95, p<.001\right)$ were significantly higher for those in Group III and IV than those in Group I and II (Table 1). 
Table 1

Comparison of general characteristics among physical activity groups at baseline $(N=10,588)$

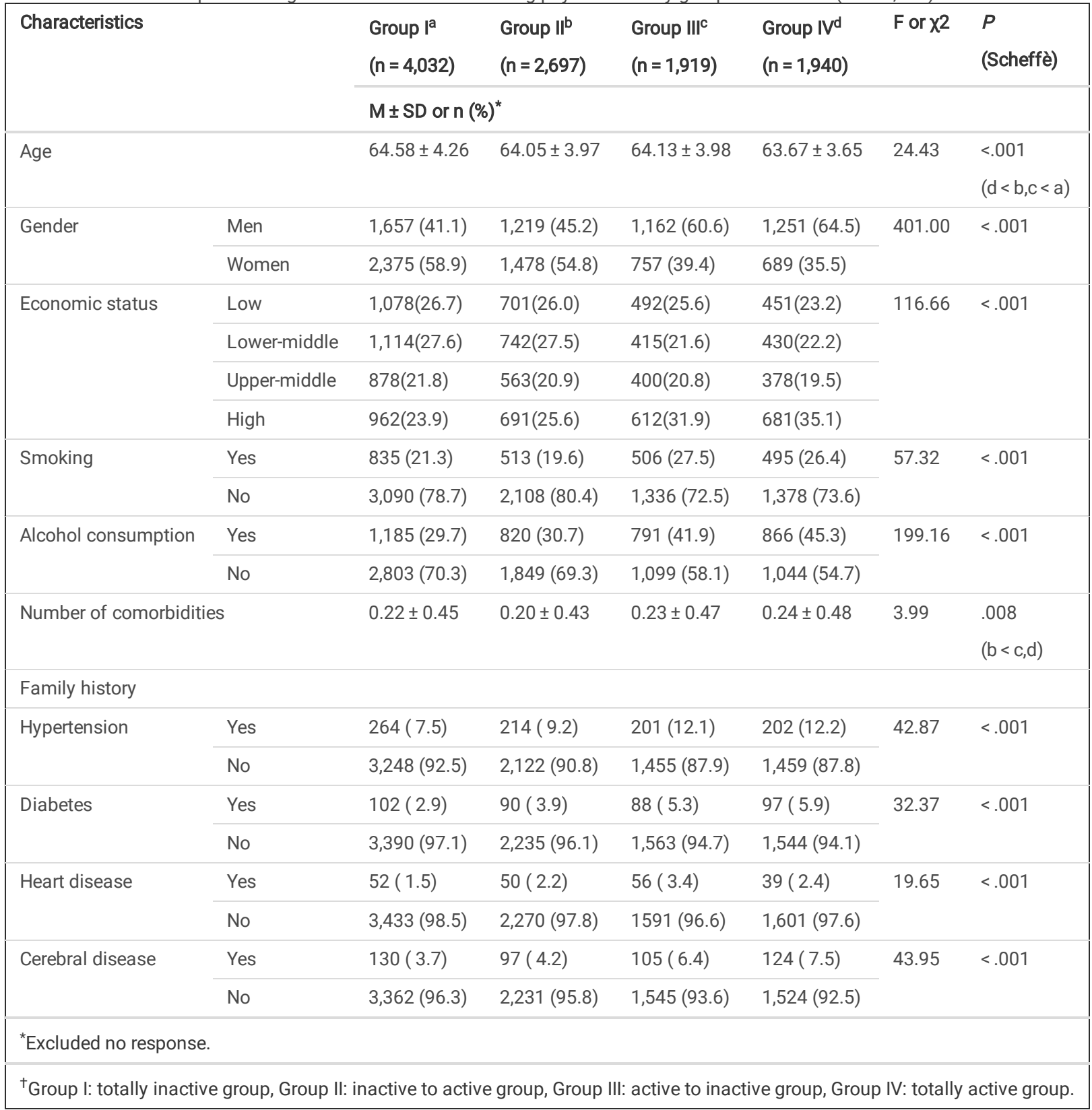

\section{Comparison of cardiovascular indicators among physical activity groups at baseline and after 12 years}

No significant differences were found in the rates of uncontrolled systolic BP (19.7-22.2\%) across 4 groups at baseline; however, the rates of uncontrolled systolic BP were significantly different between the groups after 12 years $\left(\chi^{2}=17.07, p<.001\right)$. Group IV had the lowest rate (4.6\%) of uncontrolled systolic BP, and Group I had the highest (7.1\%). There were no significant differences in the rates of uncontrolled diastolic BP (19.3-20.0\%) across the 4 groups at baseline; however, the rates of uncontrolled diastolic BP were significantly different across the groups after 12 years $\left(\chi^{2}=10.89, p=.012\right)$. Group IV had the lowest rate (2.6\%) of uncontrolled diastolic BP, and Group I had the highest (3.9\%).

As for the glucose level, there were significant differences among 4 groups both at baseline $\left(\chi^{2}=9.00, p=.029\right)$ and after 12 years $\left(\chi^{2}=10.37, p=.016\right)$. Regarding BMI, there were also significant differences among the 4 groups at baseline $\left(\chi^{2}=11.61, p=.009\right)$ and after 12 years $\left(\chi^{2}=16.57, p<.001\right)$. BMI was significantly higher in Group III and IV than in Group I and II at baseline and after 12 years.

Regarding total cholesterol level, no significant differences in the rates of hypercholesterolemia (53.0-55.4\%) among 4 groups at baseline were found; however, the rates of hypercholesterolemia significantly differed among the groups after 12 years $\left(X^{2}=19.05, p<.001\right)$. Group IV had the lowest rate (30.0\%) of hypercholesterolemia, and Group I had the highest (35.5\%; Table 2). 
Table 2

Comparison of cardiovascular indicators among physical activity groups at baseline and after 12 years $(N=10,588)$

\begin{tabular}{|c|c|c|c|c|c|c|c|}
\hline \multirow[t]{2}{*}{ Cardiovascular indicators } & & Group | & Group II & Group III & Group IVd & \multirow[t]{2}{*}{$F$ or $x 2$} & \multirow[t]{2}{*}{$P($ Scheffè $)$} \\
\hline & & \multicolumn{4}{|l|}{$\mathrm{M} \pm \mathrm{SD}$ or $\mathrm{n}(\%)$} & & \\
\hline \multirow[t]{6}{*}{ Systolic blood pressure (mmHg) } & Baseline & $148.22 \pm 14.38$ & $147.91 \pm 14.25$ & $147.24 \pm 13.81$ & $147.31 \pm 14.42$ & 3.00 & $.029(\mathrm{c}, \mathrm{d}<\mathrm{a})$ \\
\hline & $<160$ & $3,137(77.8)$ & $2,114(78.4)$ & $1,525(79.5)$ & $1,558(80.3)$ & \multirow[t]{2}{*}{5.69} & \multirow[t]{2}{*}{.128} \\
\hline & $160 \leq$ & $894(22.2)$ & $583(21.6)$ & $394(20.5)$ & $382(19.7)$ & & \\
\hline & After 12 yrs & $132.64 \pm 15.76$ & $132.84 \pm 14.96$ & $132.69 \pm 15.34$ & $132.54 \pm 14.61$ & \multirow{3}{*}{$\begin{array}{l}0.17 \\
17.07\end{array}$} & \multirow{3}{*}{$\begin{array}{l}.920 \\
<.001\end{array}$} \\
\hline & $<160$ & 3,741 (92.9) & $2,550(94.5)$ & $1,803(94.0)$ & $1,850(95.4)$ & & \\
\hline & $160 \leq$ & $288(7.1)$ & $147(5.5)$ & $115(6.0)$ & $90(4.6)$ & & \\
\hline \multirow[t]{6}{*}{ Diastolic blood pressure $(\mathrm{mmHg})$} & Baseline & $89.97 \pm 9.50$ & $89.94 \pm 9.33$ & $90.02 \pm 9.18$ & $90.41 \pm 9.32$ & 1.22 & .301 \\
\hline & $<100$ & $3,255(80.7)$ & $2,158(80.0)$ & $1,543(80.4)$ & $1,555(80.2)$ & \multirow[t]{2}{*}{0.64} & \multirow[t]{2}{*}{.887} \\
\hline & $100 \leq$ & $776(19.3)$ & $539(20.0)$ & $376(19.6)$ & 385 (19.8) & & \\
\hline & After 12 yrs & $78.25 \pm 10.05$ & $78.37 \pm 9.53$ & $77.62 \pm 9.92$ & $77.49 \pm 9.57$ & \multirow{3}{*}{$\begin{array}{l}4.84 \\
10.89\end{array}$} & \multirow{3}{*}{$\begin{array}{l}.002(d<a, b) \\
.012\end{array}$} \\
\hline & $<100$ & $3,870(96.1)$ & 2,622 (97.2) & 1,857 (96.8) & 1,890 (97.4) & & \\
\hline & $100 \leq$ & 159 ( 3.9$)$ & 75 ( 2.8$)$ & $61(3.2)$ & $50(2.6)$ & & \\
\hline \multirow[t]{6}{*}{ Glucose (mg/dL) } & Baseline & $101.06 \pm 33.75$ & $101.28 \pm 36.23$ & $102.79 \pm 33.38$ & $102.02 \pm 36.43$ & 1.24 & .292 \\
\hline & $<100$ & $2,445(60.8)$ & $1,691(62.8)$ & $1,120(58.4)$ & $1,171(60.5)$ & \multirow[t]{2}{*}{9.00} & \multirow[t]{2}{*}{.029} \\
\hline & $100 \leq$ & $1,579(39.2)$ & $1,003(37.2)$ & 797 (41.6) & 765 (39.5) & & \\
\hline & After 12 yrs & $106.58 \pm 28.18$ & $105.84 \pm 26.94$ & $107.86 \pm 27.34$ & $107.33 \pm 25.79$ & 2.41 & .065 \\
\hline & $<100$ & $1,960(48.6)$ & 1,335 (49.5) & $883(46.0)$ & $884(45.6)$ & 10.37 & .016 \\
\hline & $100 \leq$ & $2,072(51.4)$ & $1,362(50.5)$ & $1,035(54.0)$ & $1,055(54.4)$ & & \\
\hline \multirow[t]{6}{*}{ Body mass index $\left(\mathrm{kg} / \mathrm{m}^{2}\right)$} & Baseline & $24.59 \pm 3.11$ & $24.46 \pm 2.96$ & $24.77 \pm 2.86$ & $24.81 \pm 2.78$ & 7.05 & $<.001(b<c, d)$ \\
\hline & $<25$ & 2,283 (56.9) & $1,580(58.7)$ & $1,037(54.4)$ & $1,058(54.8)$ & \multirow[t]{2}{*}{11.61} & \multirow[t]{2}{*}{.009} \\
\hline & $25 \leq$ & $1,730(43.1)$ & $1,110(41.3)$ & $871(45.6)$ & $873(45.2)$ & & \\
\hline & After 12 yrs & $24.05 \pm 3.30$ & $23.98 \pm 3.09$ & $24.28 \pm 3.04$ & $24.30 \pm 2.96$ & 6.21 & $<.001(\mathrm{a}, \mathrm{b}<\mathrm{c}, \mathrm{d})$ \\
\hline & $<25$ & $2,543(63.4)$ & $1,763(65.7)$ & $1,168(61.1)$ & $1,172(60.6)$ & 16.57 & $<.001$ \\
\hline & $25 \leq$ & $1,466(36.6)$ & $920(34.3)$ & 743 (38.9) & $763(39.4)$ & & \\
\hline \multirow[t]{6}{*}{ Total cholesterol (mg/dL) } & Baseline & $205.84 \pm 39.64$ & $206.40 \pm 40.11$ & $206.20 \pm 38.46$ & $205.07 \pm 38.33$ & 0.47 & .702 \\
\hline & $<200$ & $1,870(46.5)$ & $1,203(44.6)$ & $892(46.5)$ & $909(47.0)$ & \multirow[t]{2}{*}{3.42} & \multirow[t]{2}{*}{.332} \\
\hline & $200 \leq$ & $2,153(53.5)$ & $1,493(55.4)$ & $1,025(53.5)$ & $1,024(53.0)$ & & \\
\hline & After 12 yrs & $187.69 \pm 39.37$ & $187.22 \pm 37.80$ & $184.38 \pm 38.99$ & $183.13 \pm 36.90$ & 8.20 & $<.001(\mathrm{c}, \mathrm{d}<\mathrm{a}, \mathrm{b})$ \\
\hline & $<200$ & $2,601(64.5)$ & $1,760(65.3)$ & $1285(67.0)$ & $1,356(70.0)$ & \multirow[t]{2}{*}{19.05} & \multirow[t]{2}{*}{$<.001$} \\
\hline & $200 \leq$ & $1,431(35.5)$ & $937(34.7)$ & $633(33.0)$ & $582(30.0)$ & & \\
\hline
\end{tabular}

\section{Benefits of physical activity on cardiovascular indicators}

We examined the longitudinal effects of physical activity on BP, glucose, BMI, and total cholesterol levels of the participants using the Kaplan-Meier analysis (Figs. 1 \& 2). The length of time for changing from controlled to uncontrolled BP and glucose was significantly different among the 4 groups. Specifically, the length of time for changing to uncontrolled BP was significantly longer in Group IV than in Group I ( 7.72 years; $\chi^{2}=16.56, p=.001$ ), and the length of time to change to uncontrolled glucose was significantly longer in Group II than in Group I $\left(\chi^{2}=15.77, p=.001\right)$.

As the results of the Cox proportional hazard model (Table 3), after adjusting for the covariates (i.e., age, gender, economic status, smoking, alcohol consumption, number of comorbidities, and family history), those in Group IV had 12.9\% lower risk of having uncontrolled BP than those in Group I (HR = 


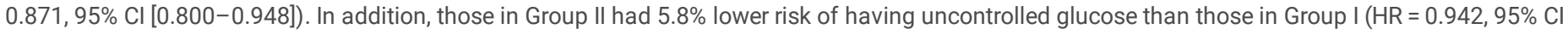
[0.888-0.999]).

Table 3

Effects of physical activity on cardiovascular indicators in older adults with hypertension

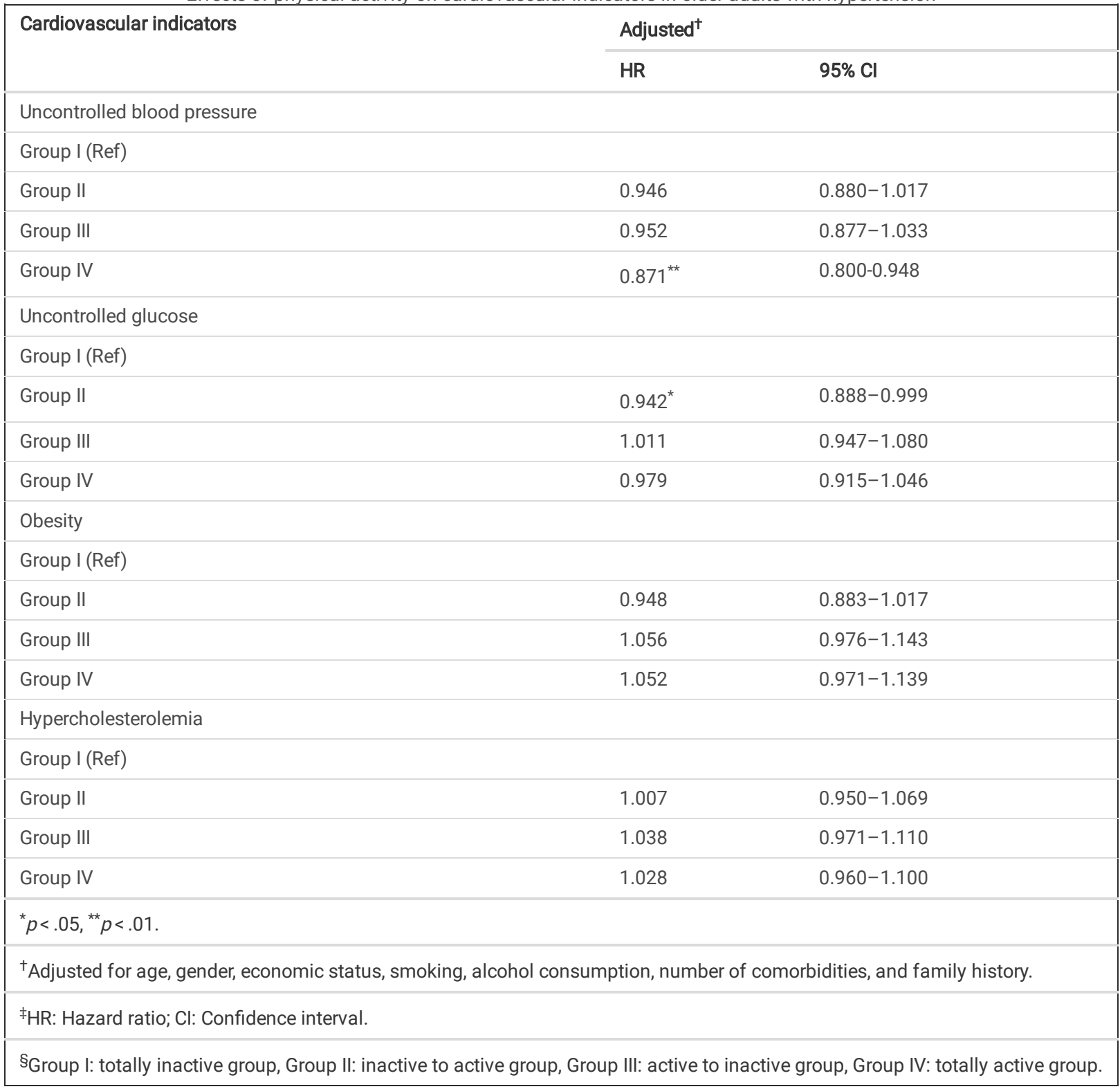

\section{Discussion}

This secondary data analysis of a prospective longitudinal study examined the benefits of physical activity over 12 years on the cardiovascular risk factors in a sample of older adults with hypertension living in the community. Our results demonstrated that the group with consistent and more strenuous physical activity had a significantly lower risk of having uncontrolled BP than the group who did not engage in any specific physical activity over 12 years. In addition, the group whose physical activity level changed from inactive to active showed a lower risk of having uncontrolled glucose levels than the group that did not engage in any physical activity over 12 years.

These results support previous research indicating that regular physical activity can lower BP and blood glucose and reduce CVD risks [11, 18-20]. Oxygen, supplied to the body during physical activity, strengthens the muscles of the cardiovascular system and is effective in improving peripheral vascular resistance associated with CVD indicators, such as hypertension and diabetes [21]. A recent study examined the effects of physical activity on CVD and mortality that used data from 17 countries and 130,843 people and concluded that all types of physical activity could be effective in reducing CVD risks and overall mortality [22].

The characteristic feature of a long-term hypertensive heart is a compensatory increase in left ventricular wall thickness (hypertrophy) that is also considered to be an independent predictor of uncontrolled hypertension [19]. If this condition persists, chronic pressure overload can lead to concentric left ventricular hypertrophy (LVH), compensatory insufficiency, and subsequent chronic heart failure and CVD events [23]. Although the exact mechanism for this process has yet to be identified, physical activity can help prevent LVH or advanced paradoxical regression in those with hypertension [19]. A study of 454 adults from 17 
hypertension units (aged 18-45 years; 281 sedentary vs. 173 active) with a long-term (median follow-up of 8.3 years) prospective observation showed that sustained regular physical activity significantly decreased BP and prevented the development of LVH [24]. In the present study, both those who constantly participated in physical activity and those who changed from being inactive to engaging in physical activity showed beneficial results related to glucose control, one of the CVD indicators. Therefore, healthcare providers should emphasize the importance of sustained regular physical activity and encourage those are not to begin participating in physical activity, as it is a critical strategy for controlling high BP and reducing the risks of CVD events in older adults with hypertension.

However, in this study, we did not identify clear evidence of the effects of physical activity on obesity or hypercholesterolemia. We defined obesity as having a $\mathrm{BMI} \geq 25 \mathrm{~kg} / \mathrm{m}^{2}$; however, previous research revealed that older adults improved overall bodily functions when they have a high BMI, such as $30 \mathrm{~kg} / \mathrm{m}^{2}$ or over [25]. Therefore, a new standardized value for BMI in older adults needs to be established, and research is needed to identify the recommended range of BMI that can be maintained with appropriate daily physical activity and can prevent CVD events in older adults with hypertension. Low-dose cholesterol medications are commonly used by patients with hypertension since they reduce CVD and atherosclerotic risks [26]. Our sample included older adults diagnosed with hypertension; thus, they may have been prescribed cholesterol-lowering medications, which could have biased the results of this study. Additional research is needed that can control for the effects of diverse medications taken by the population of older adults.

This study has several limitations. First, this was secondary data analysis, and the responses about physical activity were self-reported by older adults so that they may have been inaccurate or varied from their actual physical activity status. Second, this study did not include information on the participants' use of medical facilities, such as hospital visits, and information on medication use. Research should be conducted that examines the diverse methods of treating hypertension in the older adult population. Regardless, this study's strength is the emphasis on the benefits of physical activity as a non-pharmacological intervention by investigating the effects on CVD indicators over a period of 12 years in a sample of older adults with hypertension living in the community.

\section{Conclusions}

Physical activity is one of the most important non-pharmacological and self-management interventions that can be easily implemented with older adults with hypertension in the community. Our findings indicate that continuous participation in physical activity can significantly lower the long-term CVD indicators in older adults. Healthcare providers should be aware of the importance of physical activity for older adults and encourage them to engage in and maintain it consistently for improved long-term cardio-metabolic outcomes.

\section{Abbreviations}

BMI: Body Mass Index; BP: Blood Pressure; CVD: Cardiovascular Disease; LVH; Left Ventricular Hypertrophy

\section{Declarations}

\section{Acknowledgements}

Not applicable

\section{Funding}

This work was supported by the National Research Foundation of Korea (NRF) grant funded by the Korea government (MSIT) (No. NRF-2019R1F1A1063148) and research grant in 2019 from the Department of Nursing Science, Graduate School, Ajou University.

\section{Availability of data and materials}

The data that support the findings of this study are available from National Health Insurance Service but restrictions apply to the availability of these data, which were used under license for the current study, and so are not publicly available. Data are however available from the authors upon reasonable request and with permission of National Health Insurance Service (https://nhiss.nhis.or.kr/bd/ab/bdaba001cv.do).

\section{Authors' contributions}

Conceptualization: Jeong-Ah Ahn

Data curation: Jeong-Ah Ahn and Deulle Min

Formal analysis: Jeong-Ah Ahn and Deulle Min

Funding acquisition: Jeong-Ah Ahn

Methodology: Jeong-Ah Ahn and Deulle Min

Supervision: Jeong-Ah Ahn and Deulle Min 
Writing-original draft: Jeong-Ah Ahn and Deulle Min

Writing-review \& editing: Jeong-Ah Ahn and Deulle Min

\section{Authors' information}

JA, Associate professor, College of Nursing and Research Institute of Nursing Science, Ajou University, Suwon, Korea.

DM, Assistant professor, Department of Nursing, College of Medicine, Wonkwang University, Iksan, Korea.

\section{Ethics approval and consent to participate}

The survey for the Elderly Cohort Database of the National Health Insurance Service was conducted after acquiring verbal informed consent of participants. As this study is a secondary data analysis study, it is not possible to obtain direct consent from subjects. This study was conducted with the approval of the institutional review board of Ajou University (IRB No. AJIRB-SBR-EXP-19-127). All methods were carried out in accordance with relevant guidelines and regulations.

\section{Consent for publication}

Not applicable.

\section{Competing interests}

The authors declare that they have no competing interests.

\section{References}

1. World Health Organization. Ageing and health. 5 Feb 2018. https://www.who.int/news-room/fact-sheets/detail/ageing-and-health. Accessed 04 Jan 2021.

2. Korea Statistical Information Service. Estimated population by major age group (production age population, elderly population, etc.) / nationwide. 28 Mar 2019. https://kosis.kr/statHtml/statHtml.do?

orgld=101\&tblld=DT_1BPA003\&vw_cd=\&list_id=\&scrld=\&seqNo=\&lang_mode=ko\&obj_var_id=\&itm_id=\&conn_path=B1\&path=\%252Fconts\%252Fnsportals Accessed 08 Dec 2020.

3. Ministry of Health and Welfare. 2008 Elderly Survey. 31 Jul 2009. http://www.mohw.go.kr/react/jb/sjb030301vw.jsp? PAR_MENU_ID=03\&MENU_ID=032901\&CONT_SEQ=336618. Accessed 08 Dec 2020.

4. Ministry of Health and Welfare. 2017 Elderly Survey. 30 May 2018. http://www.mohw.go.kr/react/jb/sjb030301vw.jsp? PAR_MENU_ID=03\&MENU_ID=032901\&page=1\&CONT_SEQ=344953. Accessed 08 Dec 2020.

5. Schuler G, Adams V, Goto Y. Role of exercise in the prevention of cardiovascular disease: results, mechanisms, and new perspectives. Eur Heart J. 2013;34(24):1790-9. https://doi.org/10.1093/eurheartj/eht111.

6. World Health Organization. Hypertension. 13 Sep 2019. https://www.who.int/news-room/fact-sheets/detail/hypertension. Accessed 08 Dec 2020.

7. World Health Organization. Cardiovascular diseases. 17 May 2017. https://www.who.int/news-room/fact-sheets/detail/cardiovascular-diseases-(CVDs). Accessed 09 Dec 2020.

8. Brunzell JD, et al. Lipoprotein management in patients with cardiometabolic risk: consensus statement from the American Diabetes Association and the American College of Cardiology Foundation. Diabetes Care. 2008;31(4):811-22. https://doi.org/10.2337/dc08-9018.

9. Nelson RH. Hyperlipidemia as a risk factor for cardiovascular disease. Prim Care. 2013;40(1):195-211. https://doi.org/10.1016/j.pop.2012.11.003.

10. Williams PT, Thompson PD. Walking versus running for hypertension, cholesterol, and diabetes mellitus risk reduction. Arterioscler Thromb Vasc Biol. 2013;33(5):1085-91. https://doi.org/10.1161/ATVBAHA.112.

11. Börjesson M, Onerup A, Lundqvist S, Dahlöf B. Physical activity and exercise lower blood pressure in individuals with hypertension: narrative review of 27 RCTs. Br J Sports Med. 2016;50(6):356-61. https://doi.org/10.1136/bjsports-2015-095786.

12. Arca EA, Martinelli B, Martin LC, Waisberg CB, Franco RJ. Aquatic exercise is as effective as dry land training to blood pressure reduction in postmenopausal hypertensive women. Physiother Res Int. 2014;19(2):93-8. https://doi.org/10.1002/pri.1565.

13. Krustrup P, Randers MB, Andersen LJ, Jackman SR, Bangsbo J, Hansen PR. Soccer improves fitness and attenuates cardiovascular risk factors in hypertensive men. Med Sci Sports Exerc. 2013;45(3):553-60. https://doi.org/10.1249/MSS.0b013e3182777051.

14. Hernandes NA, Probst VS, Da Silva RA Jr, Januário RS, Pitta F, Teixeira DC. Physical activity in daily life in physically independent elderly participating in community-based exercise program. Braz J Phys Ther. 2013;17(1):57-63. https://doi.org/10.1590/s1413-35552012005000055.

15. Mancia G, et al. 2007 Guidelines for the management of arterial hypertension: The Task Force for the Management of Arterial Hypertension of the European Society of Hypertension (ESH) and of the European Society of Cardiology (ESC). Eur Heart J. 2007;28(12):1462-536. 
16. American Diabetes Association. Diagnosis and classification of diabetes mellitus. Diabetes care. 2009;32(Suppl 1):S62-7. https://doi.org/10.2337/dc14S081.

17. Weisell RC. Body mass index as an indicator of obesity. Asia Pac J Clin Nutr. 2002;11(Suppl 8):S681-4. https://doi.org/10.1046/j.1440-6047.11.s8.5.x.

18. Sigal RJ, et al. Physical activity and diabetes. Can J Diabetes. 2013;37(Suppl 1):S40-4. https://doi.org/10.1016/j.jcjd.2013.01.018.

19. Hegde SM, Solomon SD. Influence of Physical Activity on Hypertension and Cardiac Structure and Function. Curr Hypertens Rep. 2015;17(10):77. https://doi.org/10.1007/s11906-015-0588-3.

20. Ansah JP, Inn RLH, Ahmad S. An evaluation of the impact of aggressive hypertension, diabetes and smoking cessation management on CVD outcomes at the population level: a dynamic simulation analysis. BMC Public Health. 2019;19(1):1105. https://doi.org/10.1186/s12889-019-7429-2.

21. Nyberg M, Gliemann L, Hellsten Y. Vascular function in health, hypertension, and diabetes: effect of physical activity on skeletal muscle microcirculation. Scand J Med Sci Sports. 2015;25(Suppl 4):S60-73. https://doi.org/10.1111/sms.12591.

22. Lear SA, et al. The effect of physical activity on mortality and cardiovascular disease in 130000 people from 17 high-income, middle-income, and lowincome countries: the PURE study. Lancet. 2017;390(10113):2643-54. https://doi.org/10.1016/S0140-6736(17)31634-3.

23. Burchfield JS, Xie M, Hill JA. Pathological ventricular remodeling: mechanisms: part 1 of 2. Circulation. 2013;128(4):388-400. https://doi.org/10.1161/CIRCULATIONAHA.113.001878.

24. Palatini P, et al. Regular physical activity prevents development of left ventricular hypertrophy in hypertension. Eur Heart J. 2009;30(2):225-32. https://doi.org/10.1093/eurheartj/ehn533.

25. Bahat G, et al. Which body mass index (BMI) is better in the elderly for functional status? Arch Gerontol Geriatr. 2012;54(1):78-81. https://doi.org/10.1016/j.archger.2011.04.019.

26. Kanaki Al, et al. Effects of low-dose atorvastatin on arterial stiffness and central aortic pressure augmentation in patients with hypertension and hypercholesterolemia. Am J Hypertens. 2013;26(5):608-16. https://doi.org/10.1093/ajh/hps098.

\section{Figures}

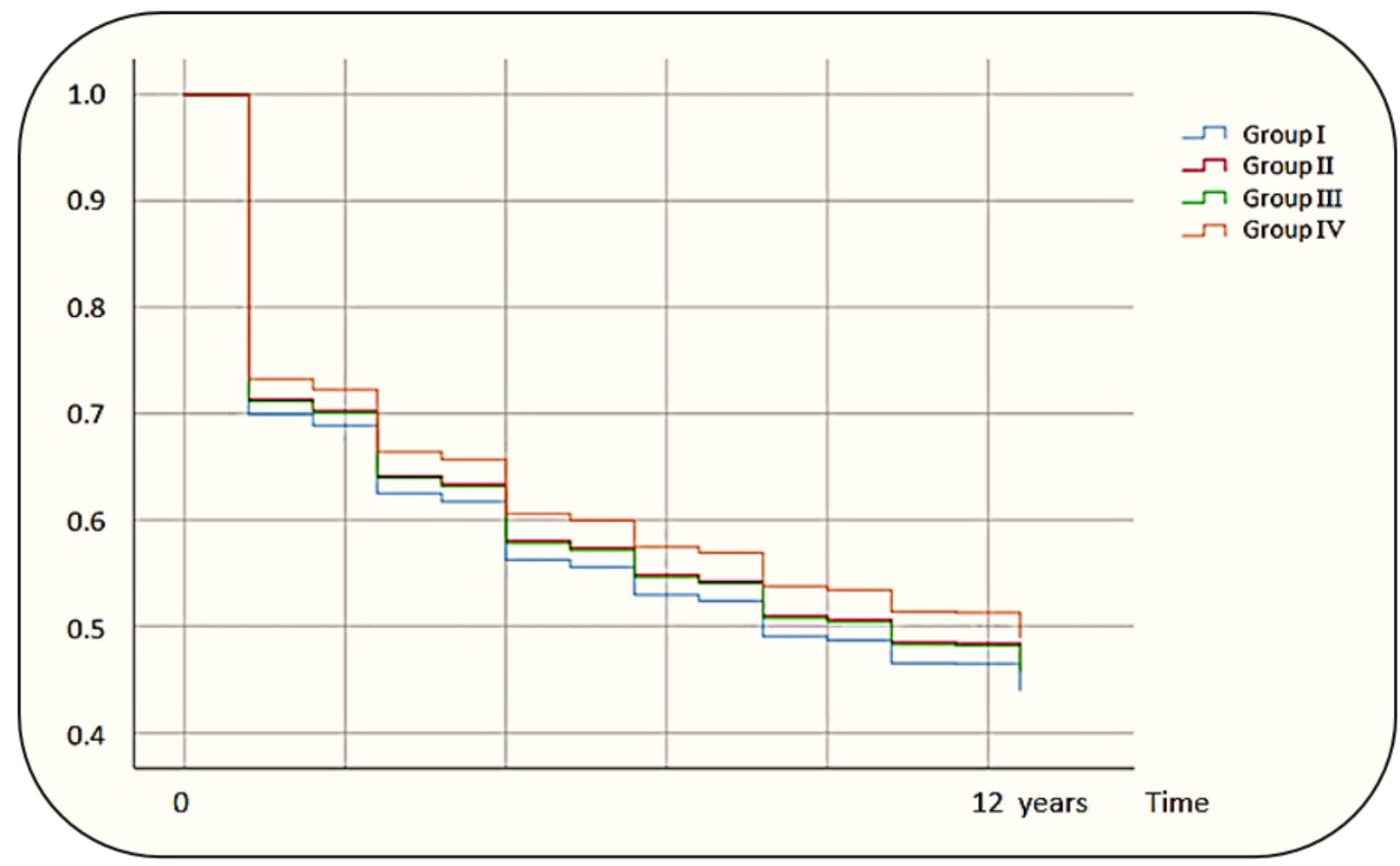

Figure 1

Uncontrolled blood pressure changes over time 


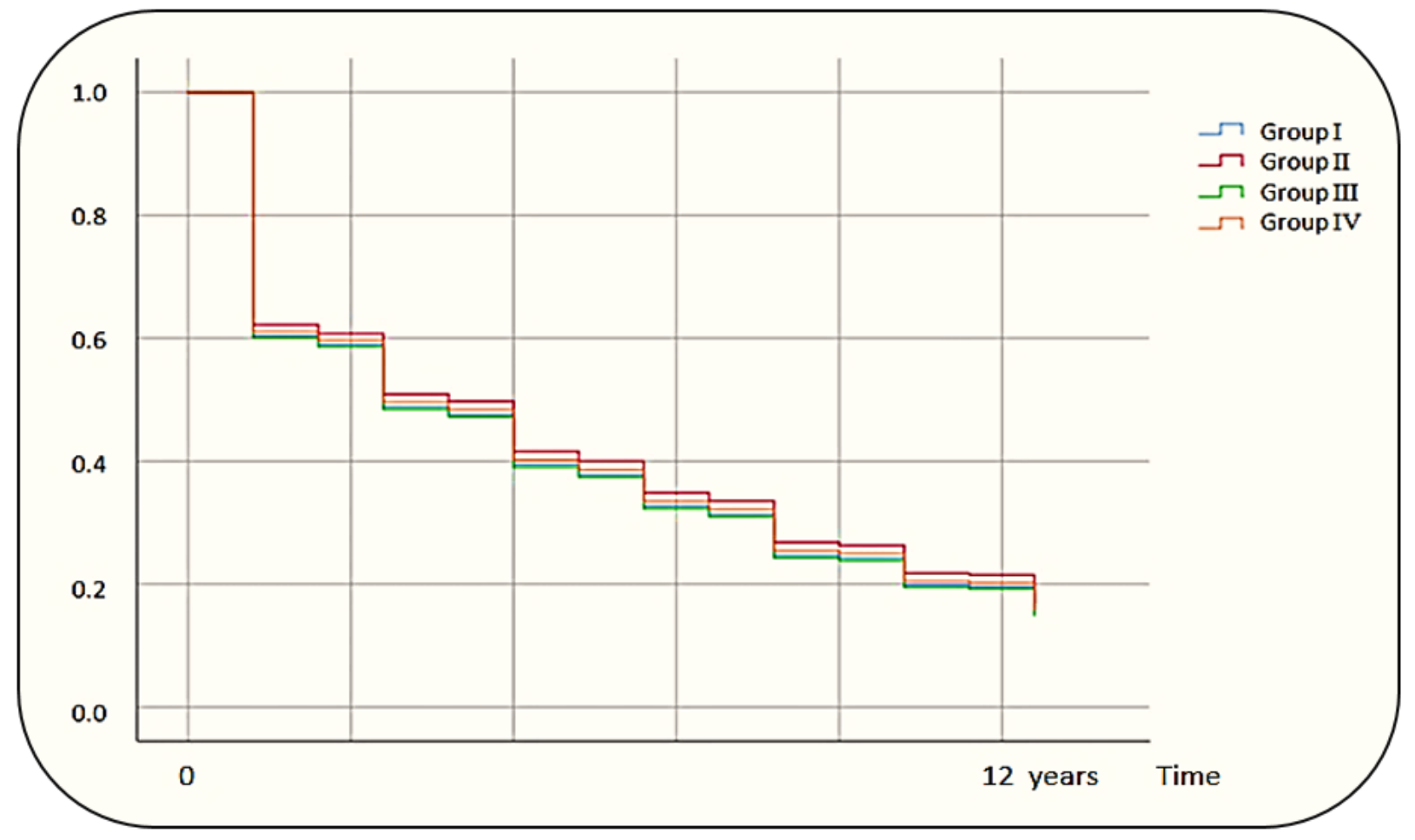

Figure 2

Uncontrolled glucose changes over time 